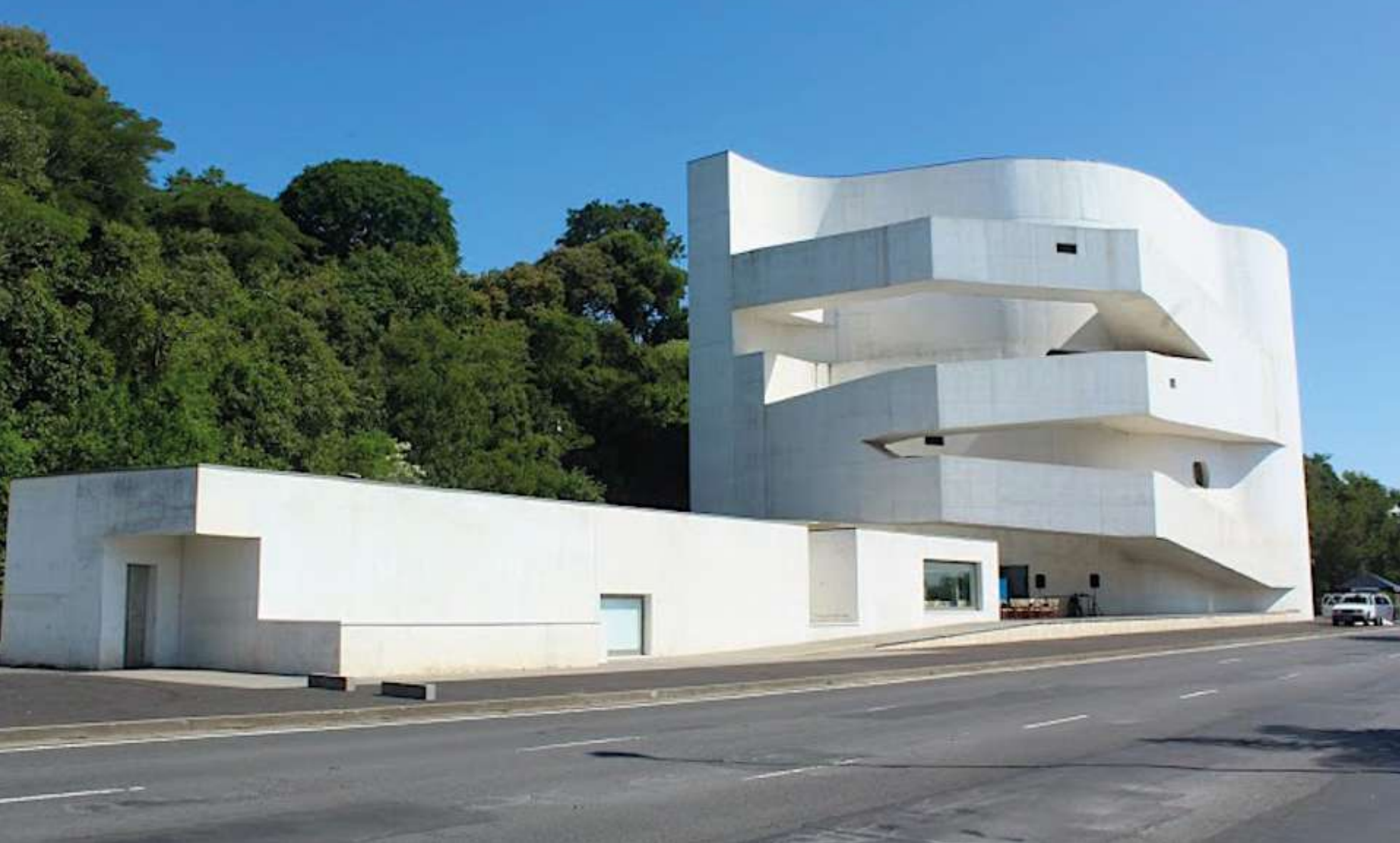

Figura 1. Vista de la Fundación Iberê Camargo. Fuente: Fotografía del autor (2018).

\title{
South American Way \\ Los equipamientos culturales proyectados por arquitectos extranjeros en Brasil
}

South American Way

Os equipamentos culturais projetados por arquitetos estranjeiros no Brasil

The South American Way

The cultural facilities designed by foreign achitects in Brazil

Ivo Renato Giroto

Investigador Postdoctoral del Departamento de Historia y Estética del Proyecto, Facultad de Arquitectura y Urbanismo,

Universidade de São Paulo (USP)/ Fundação de Amparo á Pesquisa do Estado de São Paulo (FAPESP), São Paulo, Brasil igiroto@gmail.com | https://orcid.org/0000-0002-5062-0107

Artículo recibido el 08 de abril de 2019 y aceptado el 26 de junio de 2019

DOl: https://doi.org/10.22320/07196466.2019.37.055.04 


\section{Resumen}

El artículo propone una reflexión acerca de una serie de obras de equipamientos culturales de gran visibilidad, proyectadas en los últimos años en Brasil por reconocidos arquitectos extranjeros. A partir de un análisis de la mirada extranjera sobre el país, el texto discute como arquitectos provenientes de contextos socioculturales distintos responden a las especificidades del lugar y las posibilidades de transformación cultural, urbana y arquitectónica que sus obras pueden contener. Como telón de fondo, contextualiza aspectos de la formación cultural de los paises latinoamericanos, además de cuestionar la visión que históricamente se ha construido hacia el subcontinente. Para tanto, investiga los embates $y$ diálogos culturales presentes en la Fundación Iberê Camargo (1998-2008), de Álvaro Siza; en la Ciudad de las Artes (2002-2013), de Christian de Portzamparc; en el Museo del Mañana (2011-2015), de Santiago Calatrava; y en el Museo de la Imagen y del Sonido (2009-en construcción), de Diller Sofidio + Renfro. Estas obras forman parte de proyectos políticos y urbanos más amplios, que ciertamente resuenan en miradas que, si no están constituidas desde Brasil, construyen narrativas sobre como el país es visto o como se gustaría que fuera visto.

\section{Resumo}

0 artigo propõe uma reflexão acerca de uma série de obras de equipamentos culturais com grande visibilidade, projetadas nos últimos anos no Brasil por arquitetos estrangeiros reconhecidos. A partir de uma análise da perspectiva estrangeira sobre 0 país, o texto discute como arquitetos provenientes de distintos contextos socioculturais respondem às especificidades do lugar e às possibilidades de transformação cultural, urbana e arquitetônica que suas obras podem conter. Como plano de fundo, contextualizar aspectos de formação cultural dos países latino americanos, além de questionar a visão historicamente construída sobre o subcontinente. Para tanto, investiga-se os debates e diálogos culturais presentes na Fundação lberê Camargo (1998-2008), de Álvaro Siza; na Cidade das Artes (2002-2003), de Cristian de Portzamparc; no Museu do Amanhã (20112015) de Santiago Calatrava; e no Museu da Imagem de do Som (2009 - em construção), de Diller Sofidio + Renfro. Estas obras formam parte de um projeto político e urbano mais amplo, que certamente resumem uma perspectiva que, se não foi construída a partir do Brasil, constroem uma narrativa sobre como o país é visto ou gostaria de ser visto.

\section{Abstract}

This article proposes a reflection on a series of highly visible cultural facility projects designed in recent years in Brazil by renowned foreign architects. Based on an analysis of the foreign view of the country, the text discusses how architects from different sociocultural contexts respond to the distinctive characteristics of the place, and the possibilities for cultural, urban and architectural transformation that their works may contain. As a backdrop, it contextualizes aspects of the cultural background of Latin American countries, in addition to questioning the vision that has historically been constructed of the subcontinent. To this end, the article investigates the confrontation and cultural dialogues in: the lberê Camargo Foundation (1998-2008), by Álvaro Siza; the City of the Arts (2002-2013), by Christian de Portzamparc; the Museum of Tomorrow (2011-2015), by Santiago Calatrava; and the Museum of Image and Sound (2009-under construction), by Diller Sofidio + Renfro. These works are part of broader political and urban projects, which certainly resonate with points of view that, although they are not founded in Brazil, build narratives about how the country is seen or how it would like to be seen.

\section{Palabras claves}

Arquitectura contemporánea; equipamientos culturales, museos, Brasil

\section{Palavras chaves}

Arquitetura contemporânea; equipamento cultural; museus; Brasil

\section{Keywords}

Contemporary architecture, cultural facilities, museums, Brazil 
* Fundação de Amparo à Pesquisa do Estado de São Paulo - FAPESP (Proceso n. 2016/21108-2]

\section{Introducción: la presencia extranjera entre nosotros*}

A lo largo de las dos primeras décadas del siglo XXI, la llegada de arquitectos reconocidos como celebridades en el contexto internacional ha movido el escenario de la arquitectura brasileña, hasta entonces cerrado en sus propias dinámicas y cuestiones internas. Este artículo propone, en ese contexto, una reflexión acerca de una serie de obras de equipamientos culturales de gran visibilidad, proyectadas recientemente por reconocidos arquitectos extranjeros, que pasaron a integrar el acervo de la arquitectura contemporánea en Brasil.

Su presencia instiga una serie de discusiones posibles: ¿cómo es que arquitectos provenientes de contextos socioculturales distintos responden a las especificidades de la condición del país?, ¿Qué clase de diálogos es posible establecer con la cultura, la historia, la ciudad, el paisaje y la tradición arquitectónica?, ¿Serán capaces de generar debates que impliquen transformaciones urbanas y que impacten en la propia cultura arquitectónica del país?

Ante todo, es importante recordar que la historia cultural latinoamericana ha sido profundamente marcada por la presencia extranjera. Más que un agente de transformación, la herencia centroeuropea es un dato fundamental de nuestra formación. La identidad cultural de nuestros países se ha constituido no como recuperación de una identidad originaria, autóctona, sino a partir de una relación umbilical con los colonizadores ibéricos. De hecho, los esfuerzos de construcción identitaria observados en las jóvenes naciones latinoamericanas en el siglo XIX, en gran medida, fueron para demostrarle a Europa -muchas veces que más que a nosotros mismos- nuestro valor como nación y como cultura independiente, construida con valores "civilizatorios" equivalentes y, a la vez, distintos a los de la matriz (Perrone-Moisés, 1997, pp. 246-247).

Los movimientos pendulares entre localismo y cosmopolitismo, que el crítico literario brasileño Antonio Candido reconocía como latentes en la evolución de la vida espiritual de Brasil (1985, p. 109), asumieron otra complejidad en el siglo XX, con la llegada de las vanguardias modernas en el arte y la arquitectura, y de la importante llegada de arquitectos inmigrantes de Europa a los diversos países latinoamericanos.

Le Corbusier, por ejemplo, está considerado como el paradigma de arquitecto forastero en América, especialmente a partir de sus visitas a Buenos Aires, Montevideo, Sao Paulo y Río de Janeiro en 1929, como también gracias a sus posteriores actuaciones como consultor invitado para proyectos gubernamentales en Brasil, en 1936, y a su proyecto para el Plan Director de Bogotá entre 1947 y 1951. El recuerdo de su presencia rememora, inevitablemente, la dimensión de 
su herencia en la arquitectura moderna latinoamericana, sobre todo de Brasil, donde sus ideas han sido decisivas para la construcción de una producción moderna autónoma e internacionalmente consagrada.

Pero hay que diferenciar el establecimiento de arquitectos provenientes de otros paises de los que, a ejemplo del maestro francés, han venido por tiempo limitado y en razón de encargos específicos. Las distintas intensidades de contacto y conocimiento del lugar generan interpretaciones y respuestas igualmente diferentes.

Aunque no sea nueva, la circulación internacional de obras -y no necesariamente de sus autores- es un fenómeno que ha crecido en progresión geométrica a partir de la consolidación de la globalización, particularmente a partir de las dos últimas décadas del siglo pasado.

Enelcasoespecifico deBrasil, el contexto deredemocratización y crisis económica a lo largo de los años 1980 retardó la inserción plena de la nación en las dinámicas globalizadas. Esto ya se había experimentado años antes en los países denominados "desarrollados" y se ha convertido en una tendencia apreciable en este pais en la primera década del siglo XXI, debido a la coyuntura económica favorable y la visibilidad internacional ofrecida por el Mundial de Fútbol de 2014 y las Olimpiadas de Río de Janeiro de 2016.

Edificaciones de distintos programas fueron diseñadas por arquitectos extranjeros, interesados en "hincar el diente" en un mercado emergente y entonces prometedor. Entre otros ejemplos de obras construidas, y sin contar los muchos proyectos malogrados, son destacables: las múltiples torres corporativas que grandes oficinas especializadas -como Skidmore, Owings \& Merril (SOM), Kohn, Pedersen \& Fox, Pickard Chilton, Arquitectónica, Cesar Pelli, y Norman Foster- construyeron en metrópolis como São Paulo y Río de Janeiro; las igualmente especializadas obras de arquitectura deportiva, como la arena de fútbol de Salvador de Bahía (2009), de Schulitz Architekten, y el Parque Olímpico de Río de Janeiro (2011), de AECOM; edificios residenciales proyectados en Sao Paulo por Daniel Libeskind (2015) y Fermín Vázquez (2016); un lujoso hotel firmado por Jean Nouvel, actualmente en construcción en Sao Paulo; el pequeño edificio de oficinas Leblon Offices (2016), diseñado por Richard Meier en Río de Janeiro; y el conjunto polideportivo y educacional Arena do Morro (2014), de Herzog y De Meuron, en una favela de Natal, al noreste de Brasil.

Sin embargo, ninguna otra clase de obra arquitectónica alcanzó mayor repercusión en la prensa general y especializada del país que los museos y centros culturales. Su gran potencial simbólico les permite contar comúnmente con sitios de extrema visibilidad urbana, altos presupuestos, flexibilidad funcional y libertad expresiva, lo que despierta la codicia tanto de los arquitectos como de los políticos.

En los últimos años, Brasil ha experimentado un sensible aumento en la construcción de equipamientos culturales, de distintas escalas y finalidades, desde el cual ha mejorado su todavía insuficiente estructura cultural. Pero la inédita ascención de grandes museos, diseñados por arquitectos que ostentan el estatus de celebridad internacional, es un fenómeno nuevo que parece indicar la 


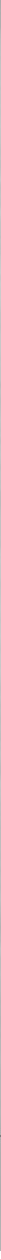

Figura 2. Montaje comparativo entre el SESC Pompeia, de Lina Bo Bardi y la rampa del Museo de Arte Contemporáneo de Niteroi (1996), de Niemeyer. Fuente: Fotografías del autor (2018).

54

inserción tardía del país en la "era de los museos". Desde las últimas décadas del siglo pasado, los museos idealizados como centros de entretenimiento, capaces de atraer hordas de visitantes, era una tendencia observada en los países de Europa y Estados Unidos, impulsados por la consolidación de la cultura posmoderna del ocio y de la industria cultural de masas (Montaner, 2003: 8).

La configuración arquitectónica de los equipamientos culturales tratados en este artículo no podría ser bien comprendida sin este (incompleto) preámbulo. A partir de una pequeña selección de obras, restringida a algunos de los equipamientos culturales de mayor impacto en el escenario contemporáneo de Brasil, el artículo propone una reflexión sobre la reciente actuación de los arquitectos extranjeros y la manera cómo estos estructuran su mirada hacia las condiciones especificas de este país.

La Fundación Iberê Camargo (1998-2008), de Álvaro Siza Vieira; la Ciudad de las Artes (2002-2013), de Christian de Portzamparc; el Museo del Mañana (2011-2015), de Santiago Calatrava; y el Museo de la Imagen y del Sonido (2009-en construcción), de Diller Sofidio + Renfro, forman parte de proyectos políticos y urbanos más amplios, que ciertamente resuenan en visiones que, si bien no han surgido en Brasil, configuran narrativas sobre cómo el país es concebido o cómo quisiera ser percibido por el mundo. 


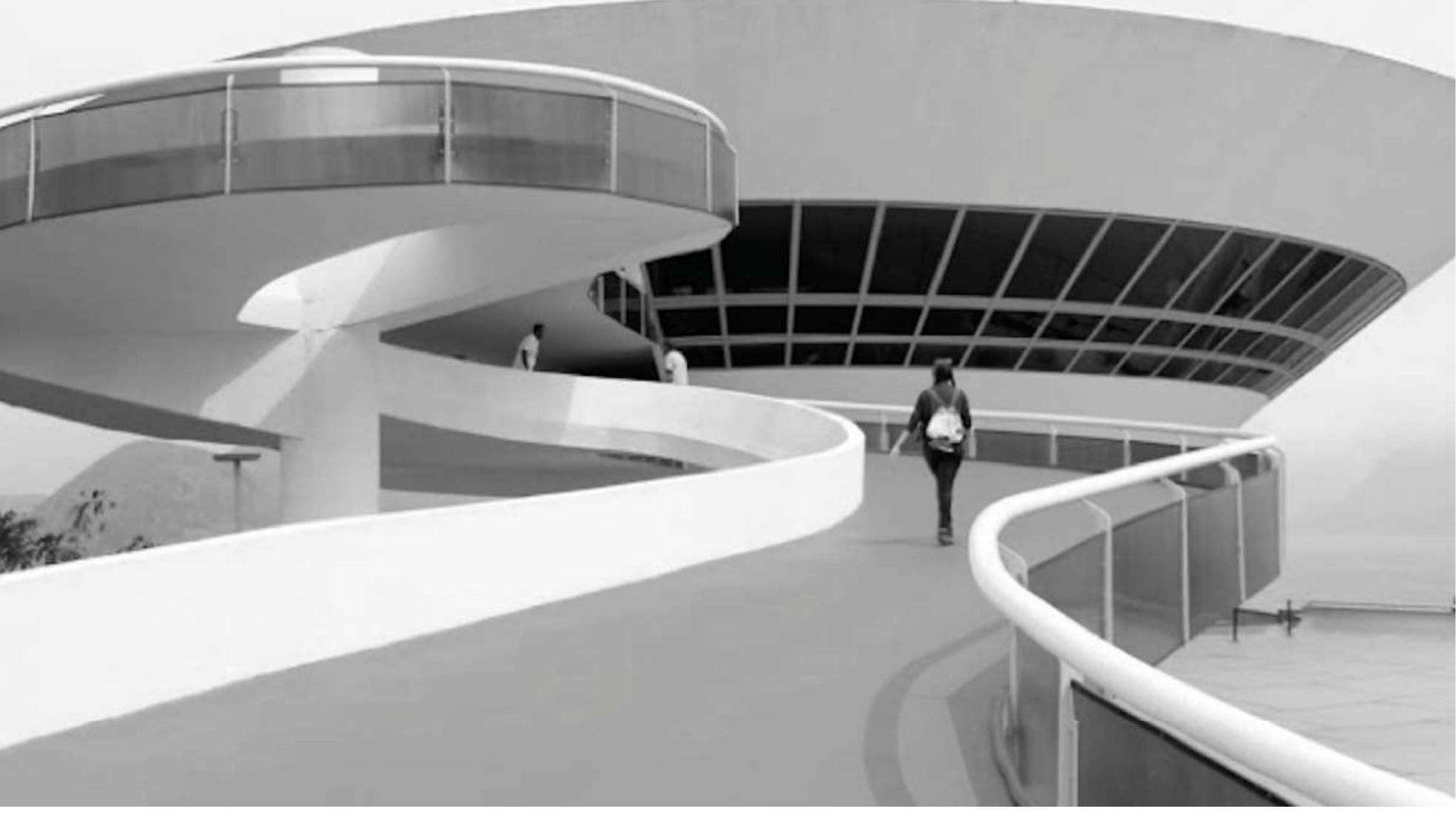

\section{Discusión: South American Way}

El proyecto desarrollado por el portugués Álvaro Siza para la sede de la fundación que abriga la obra del pintor Iberê Camargo (19141994), en Porto Alegre, inauguró una serie de museos proyectados en Brasil por arquitectos extranjeros. La fundación es privada, su construcción se ha realizado con el apoyo financiero empresarial y la elección de Siza ha sido una decisión del consejo administrador.

Esto ya coloca al edificio en una posición singular en relación a los demás aquí abordados, construidos por iniciativa estatal y costeados en su mayor parte por fondos públicos, complementados con dinero privado. De la misma manera, constituye una excepción al ser uno de los pocos museos del país integralmente dedicados a la obra de un solo artista, con la cual busca establecer parte de sus diálogos arquitectónicos.

Implantado en un terreno angosto, otrora parte de una antigua cantera, el edificio se acomoda entre un paredón rocoso y una avenida de tráfico rápido, que lo separa de las orillas del lago que baña Porto Alegre. Al depararse en tal entorno urbano, la conocida habilidad del arquitecto portugués de integrar la arquitectura al lugar, tuvo de responder a otro desafío, nada raro en las ciudades latinoamericanas: crear un contexto.

El museo se encaja en el paisaje llenando el vacío dejado por las excavaciones de la pedrera, de la cual saca provecho como generador formal de un volumen fragmentado y de marcada imposición escultórica, que rápidamente se convirtió en una de las 


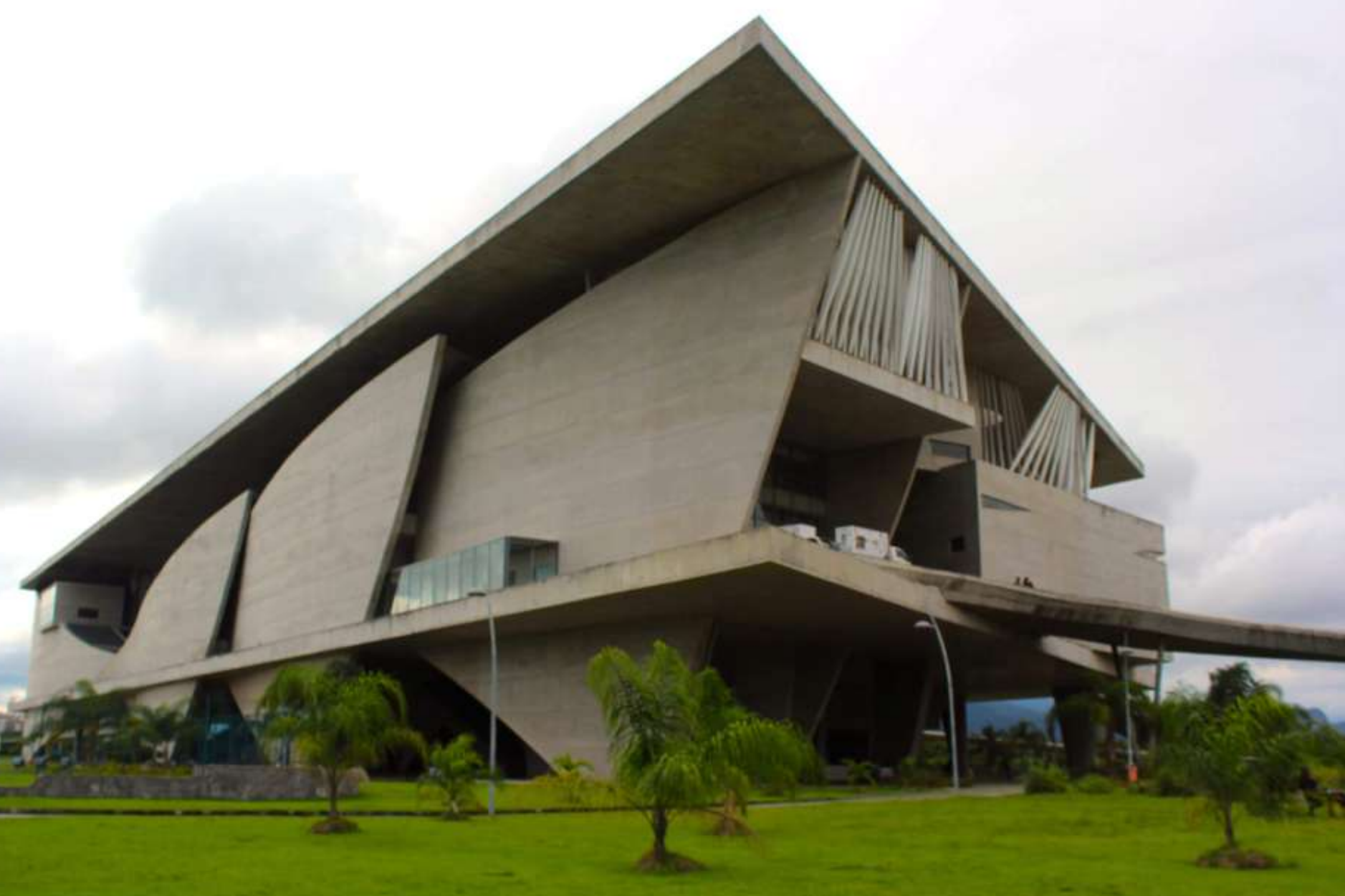

Figura 3. Vista de la Ciudad de las Artes. Fuente: Fotografía del autor (2018).

56

imágenes preferenciales de la ciudad. (Figura 1)

En las formas diseñadas por Siza, en su primera obra brasileña, subyace la profunda vinculación histórica y cultural existente entre Brasil y Portugal. Además, guardan relaciones afectivas personales y referencias profesionales que son parte inextricable de su formación:

Mi padre nació en Belém del Pará y se fue a Portugal con
12 años. He crecido con mi abuela contando historias de
Brasil, leyendo historietas del Globo Juvenil y comiendo
dulce de guayaba. (...) Affonso Eduardo Reidy, Lucio Costa
yoscarNiemeyer... Lasimágenesdeloscerros, delasfavelas...
Todo eso haquedadofijadoenmimente (Siza, 2012, p. 42)

Efectivamente, la relación de Siza con la arquitectura brasileña es antigua y remite a los tiempos en que la llegada a Portugal del catálogo de la célebre exposición Brazil Builds: architecure new and old, 1652-1942, exhibida en 1943 en el MOMA, indicaba una forma exitosa de alcanzar la modernidad sin despreciar lo vernáculo, lo tradicional y lo histórico. Así, el arquitecto recuerda: Me acuerdo que (Fernando) Távora había comprado -no sé dónde, pero no en Portugal- el libro Brazil Builds, que presentabalasconstruccionesrecientes de OscarNiemeyer, de Lúcio Costa y de otros de la vanguardia brasileña. La ponencia que él había hecho sobre eso en la escuela. marcó profundamente los espíritus, porque evocaba a Le Corbusier, que nosotros imaginábamos solo, a luchar por la modernidad. (Machabert y Beaudouin, 2009, p. 29).

Muchos autores reconocen la posibilidad de que este entramado histórico y vital haya potencializado una narrativa 
arquitectónica continuamente surcada por intensos diálogos entre las arquitecturas portuguesa y brasileña. Según Flavio Kiefer,

Siza se reconoce como un admirador de la arquitectura brasileña y cuenta que Niemeyer fue parte importante de su formación. Demostró que fue a buscar en las raíces culturales de Brasil parte de sus referencias. Ahí se puede ver, tanto rasgos de un estructuralismo-brutalista de la arquitectura paulista, cuanto la sensualidad de las curvas y muros blancos de la arquitectura de Oscar Niemeyer ${ }^{1}$ (2010, p. 130)

Otros criticos de relieve, como Ana Vaz Milheiro (2007) y Luciano Margotto (2016:208) corroboran tales aproximaciones, fundamentalmente a partir de la fuerte relación visual que el museo establece con los pasadizos abiertos de Lina Bo Bardi en el SESC Pompeia (São Paulo, 1977-86). También Kenneth Frampton identifica en los "tendones fracturados de algún monstruo calcificado" (2008, p. 93) imaginados por Siza una evocación de la obra de Bo Bardi, con resonancias del brutalismo de Le Corbusier, sobre todo en La Tourette (1956-1960) y en la Suprema Corte de Chandigarh (1952-1959).

Asimismo, las rampas colgantes y la utilización del hormigón armado, símbolo de la tradición moderna brasileña y material hasta entonces poco común en la obra de Siza, son los principales elementos que confirman la intención de referenciar la cultura arquitectónica brasileña (Figura 2). Desde esa perspectiva, Otávio Leonídio comenta:

\begin{abstract}
Al fin y al cabo, no era difícil reconocer, ya en las primeras imágenes del 'Siza brasileño', referencias más o menos explícitas a la arquitectura moderna local. ¿O acaso no estaríamos autorizados a ver en aquellas rampas de hormigón armado (sobre todo las rampas externas en voladizo, sacadas del cuerpo principal del edificio) la repercusión de la libre gestualidad y de las proezas estructurales de la arquitectura de Oscar Niemeyer, Lina Bo Bardi, entre otros? (2009, p. 34)
\end{abstract}

Referencias al repertorio moderno brasileño ya habian sido exploradas en el Pabellón que Siza diseñara para representar Portugal en la Expo 98 de Lisboa, cuya distensión de la cubierta en hormigón pretensado evoca tanto las grandes navegaciones portuguesas como las suaves curvas de Niemeyer.

La búsqueda por adquirir acentos y lenguajes ajenas es una actitud común en las obras proyectadas por Siza fuera de Portugal. En este intento de aclimatarse a ambientes que le son extraños, Rafael Moneo reconoce una estrategia basada en la manipulación de excesos y extravagancias, que transforman la arquitectura en narración, en la cual es posible identificar figuras y personajes que dialogan. Siza en tierra extraña es más esquemático que en la propia (2008, p. 218).

Pero en este caso, además de las referencias arquitectónicas, el expresionismo formal también revela un intenso diálogo con el espíritu angustiado y complejo de la pintura de lberê Camargo, materializado en el contraste entre la espacialidad laberíntica de los pasadizos cerrados con la regularidad y abertura de las salas expositivas.

La existencia inequívoca de dichos diálogos incorpora la complejidad del método proyectual de Siza, mezclando referencias diversas y mundos distintos, moviéndose [...] entre conflictos, compromisos, mestizajes, transformación (Siza, 1995, p. 


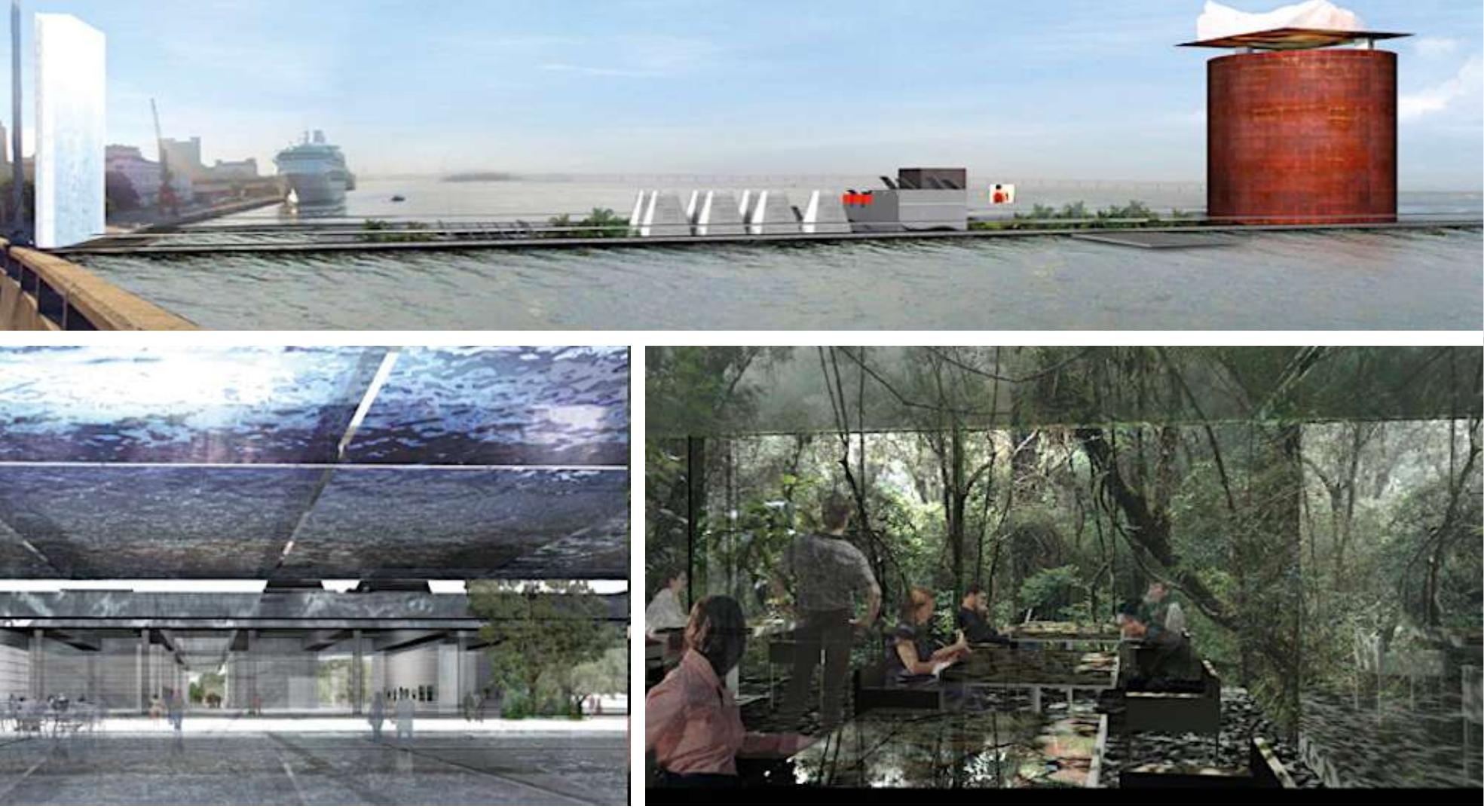

Figura 5. El exotismo del Guggenheim de Nouvel.

Fuente: Museo de Guggenheim (http://www.jeannouvel.com/projets/musee-guggenheim/).

en un gran complejo artístico dedicado a las artes musicales, inspirado en la Ciudad de la Música de Paris (1984-1995), obra del mismo Portzamparc.

El edificio está implantado en medio de un gran dispositivo vial formado por el cruce de las dos principales avenidas de Barra da Tijuca, barrio proyectado en Río de Janeiro por Lucio Costa en 1969 de acuerdo con los preceptos del urbanismo moderno. La inmensa llanura que marca 15 quilómetros entre el mar y las montañas de esta parte de Río necesitaba de un marco urbanístico que colocara personalidad urbana al monótono paisaje. Tal como el museo de Siza, una las funciones primordiales de la arquitectura de la Ciudad de las Artes era crear un contexto urbano significativo (Figura 3).

Solamente un edificio de porte e imposición monumental seria capaz de hacer frente a la vasta horizontalidad del panorama. Por tanto, Portzamparc elevó las salas de concierto y demás áreas funcionales para el primer pavimento, proporcionando más visibilidad al volumen construido. Dos grandes losas en forma de paralelogramo actúan como contención geométrica para planos serpenteantes que parten del piso bajo y definen los espacios cerrados del nivel superior. En el movimiento de las hojas ondulantes en concreto visto se puede identificar evocaciones a las formas de Niemeyer que, en palabras del arquitecto, contiene el poema del ritmo, de la proporción, pero también de la línea que baila y del volumen que envuelve (2009: 10).

Tal como en la Ciudad de la Música parisina, la espacialidad del edificio brasileño está marcada por el protagonismo de la red 
de circulaciones, creando amplios espacios de convivencia entre las salas de concierto y definiendo una combinación de varios edificios dentro de uno solo. Pero en Río se ha invertido la relación entre apertura y cerramiento observada en la obra francesa, configurando una arquitectura caracterizada por la exterioridad y por la relación abierta con el clima y el paisaje.

El piso bajo ha sido mantenido como una gran plaza cubierta, cuya alusión a los pilotis, largamente utilizados en la arquitectura moderna brasileña, es reforzada por la profusión de espejos de agua y por los mosaicos en piedra que caracterizaban los jardines del artista y paisajista Roberto Burle Marx (1909-1994). En el mismo sentido, la ambientación imaginada como extensión del espacio público recuerda a la solución que caracteriza el Museo de Arte Moderno de Río (1954) de Affonso Eduardo Reidy (1909-1964). En las dos extremidades, rampas sinuosas rememoran a las del Pabellón de Brasil para la Feria Internacional de Nueva York de 1939, proyectado por Lucio Costa y Oscar Niemeyer (Figura 4).

El propio arquitecto declara haber imaginado el edificio como una gran casa moderna brasileña, un gran mirador sobre la ciudad, un homenaje a un arquetipo de la arquitectura brasileña de los años 1950 (Portzamparc, 2013).

De la desenvoltura para manejar el repertorio moderno brasileño vendria, de acuerdo con el análisis de Otavio Leonídio (2008, p. 185), la dificultad que muchos arquitectos brasileños han encontrado al lidiar con ese proyecto. Al fin y al cabo, la postura de Portzamparc es diametralmente opuesta a la inhibición reverente con la que los arquitectos brasileños suelen mirar hacia la obra de los maestros modernos.

Con todo, Leonídio (ibídem) considera que el proyecto renueva la creencia en la capacidad potencialmente sublimadora de la forma arquitectónica excepcional en el espacio urbano, quizás el trazo más distintivo de la producción moderna brasileña.

La Ciudad de las Artes integraba una estrategia urbana que tenía por objetivo promocionar la imagen de Río de Janeiro a través de la implantación de grandes equipamientos culturales en puntos importantes de la ciudad, proyectados por arquitectos internacionalmente reconocidos. Anunciado en el año 2000, el frustrado plan de establecer en Brasil la primera filial del museo Guggenheim en el hemisferio sur formaba parte de un expediente que pretendia repetir el éxito logrado por Bilbao, con el espectacular museo de Frank Gehry, inaugurado en 1997.

La fundación americana encargó a Jean Nouvel la responsabilidad de proyectar un museo icónico. Según el propio arquitecto:

La primera condición de la existencia de este museo es su compromiso con la atracción, la obligación de satisfacer el deseo de los visitantes que acuden a verlo y lo consideran 'imprescindible' [...]. Crear algo que nunca se haya visto; crear una nueva necesidad. Tocar la fibra sensible: estamos en Río de Janeiro. Y lo sabemos. Queremos participar: el museo debe convertirse en un organismo vivo del puerto, en un monumento emblemático de la ciudad y en un lugar especial inmerso en un territorio específico (Nouvel y Jodidio, 2008, p. 440) 


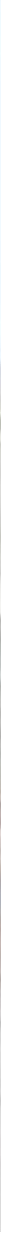

Figura 6. Vista general del Museo del Mañana sobre el muelle. Fuente: Fotografía del autor (2018).

Para cumplir tal objetivo, entre una sala expositiva y otra, trozos de selva tropical se mezclarian con referencias al paisaje decadente del puerto de la ciudad, donde el museo sería construido. Espejos de agua e incluso una cascada artificial de 30 metros de alto completarian el escenario destinado a atraer miles de visitantes cautivados por una arquitectura altamente escenográfica (Figura 5).

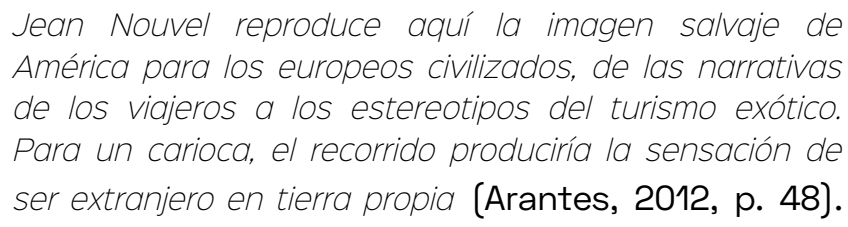

La referencia al proyecto de Nouvel es importante pues, en el mismo sitio donde había imaginado su extravagante Guggenheim tropical, Santiago Calatrava logró llevar a cabo su proyecto para el Museo del Mañana, dedicado a los temas de la sostenibilidad e inaugurado en el contexto de euforia generado por los Juegos Olimpicos.

La arquitectura de Calatrava posa como una enorme escultura urbana sobre el Pier Mauá, un gran embarcadero construido para recibir los turistas que llegarian a Brasil para el Mundial de Fútbol de Brasil en 1950, y que había quedado subutilizado a lo largo de muchas décadas.

La singular condición paisajística del muelle y su situación urbana, delante de una de las plazas más conocidas de la ciudad, amplifica el potencial icónico de la arquitectura. El museo se impone como un volumen horizontal y alargado, que termina en grandes 


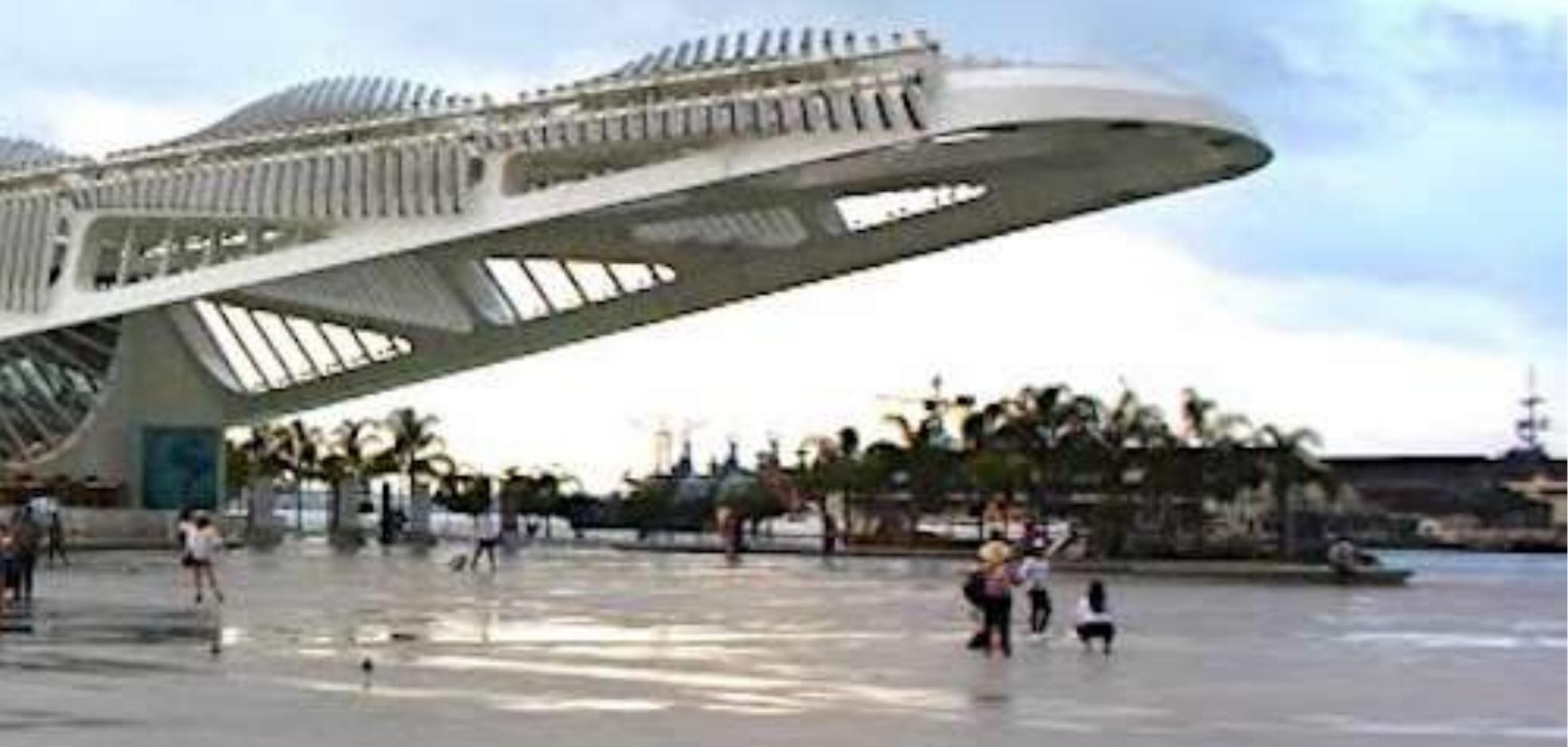

voladizos en sus dos extremidades, confiriendo ligereza a la gran masa edificada.

La relación entre obra y contexto son perceptibles solamente en la limitación de su altura, que busca preservar la vista para el Monasterio de San Benito - patrimonio barroco del siglo XVII situado en al alto de un cerro adyacente- $y$ en la intención de expandir el espacio público con la implantación de un parque de paseo alrededor del edificio (Figura 6).

Admirador declarado de Niemeyer, del compositor Heitor Villa-Lobos (1887-1959) y del guacamayo Blu, estrella de la película de animación Rio (2011) (Pessoa, 2015), el arquitecto afirma haber buscado exprimir el genius loci de la ciudad, por medio de un "monumento a la belleza, al movimiento y a la música" (Calatrava, 2012). Sin embargo, la obra deriva claramente de la conjunción entre su lenguaje propio y las condicionantes específicas del sitio.

Refiriéndose a su puente en la ciudad española de Mérida (1988-1991), el que podria servir perfectamente a su museo carioca, Calatrava afirmaba:

es como ir contra toda esa humildad apriorística de querer
sumarse alcontexto de una manera subordinada[...]. A míme
parece adecuado plantarun objeto extravagantey hacerun
alarde técnico en un contexto de subdesarrollo tecnológico
como el de Mérida. iNo sé! iProvocar! (Moix, 2016, p. 34).

En esta línea, el dinamismo que las tecnológicas "espinas solares” imprimen a la arquitectura es más un ejercicio de su 

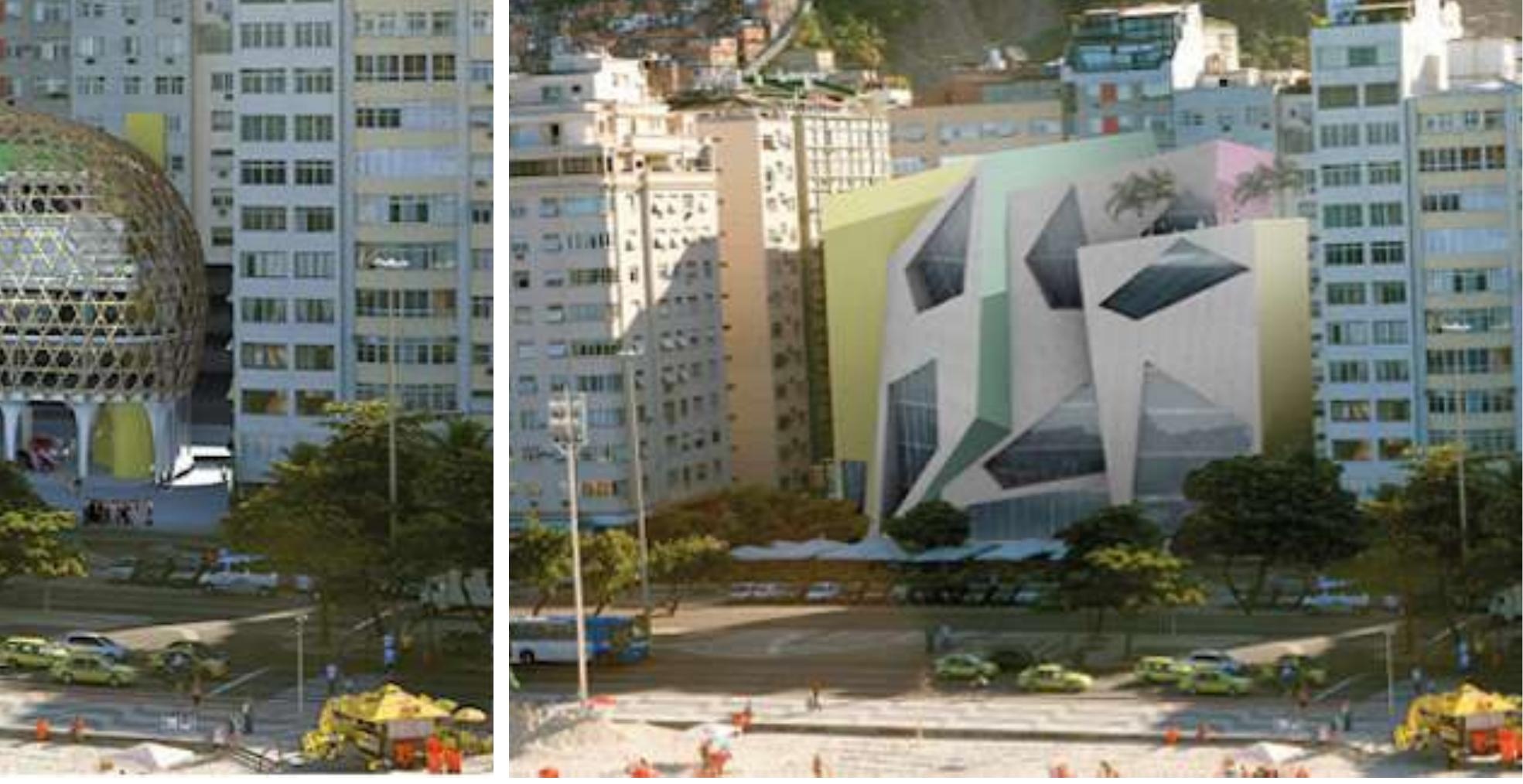

convirtiendo el edificio en una promenade architecturale integral.

El esquema, aunque se acomode bien al contexto, no parece resultar tan solo de las características intrínsecas al entorno y a su cultura artística, sino que refleja el énfasis dado por la oficina a los recorridos por la arquitectura, como lo demuestran los proyectos no ejecutados para el Eyebeam Museum of Art and Technology (2004) y para el Vagelos Education Center (2016), ambos en Nueva York (Figura 7).

El sistema de circulaciones externas que caracteriza la obra saca provecho del clima cálido y de la belleza del panorama de Río, brindando a los visitantes nuevos puntos para contemplarlo.

La escalinata abierta por veces invade los espacios internos, marcados por la integración visual entre los pavimentos y por las vistas entrecortadas del paisaje, que se abren episódicamente desde los interiores del museo como si fueran parte del contenido expuesto.

No obstante, esta relación intensa con la ciudad queda restringida a la fachada preferencial del edificio, eminentemente cerrado a la angosta calle situada detrás. La estrategia parece metaforizar la lógica del entretenimiento cultural que mueve la construcción del museo, el cual se abre a una de las zonas turísticas más conocidas del mundo, mientras da la espalda a muchos sectores de la ciudad que ni siquiera pueden contar con una sencilla biblioteca de barrio.

Por su parte, las propuestas presentadas al mismo concurso por Shigueru Ban y Daniel Libeskind fueron menos sutiles en las referencias al imaginario construido acerca de Brasil. 


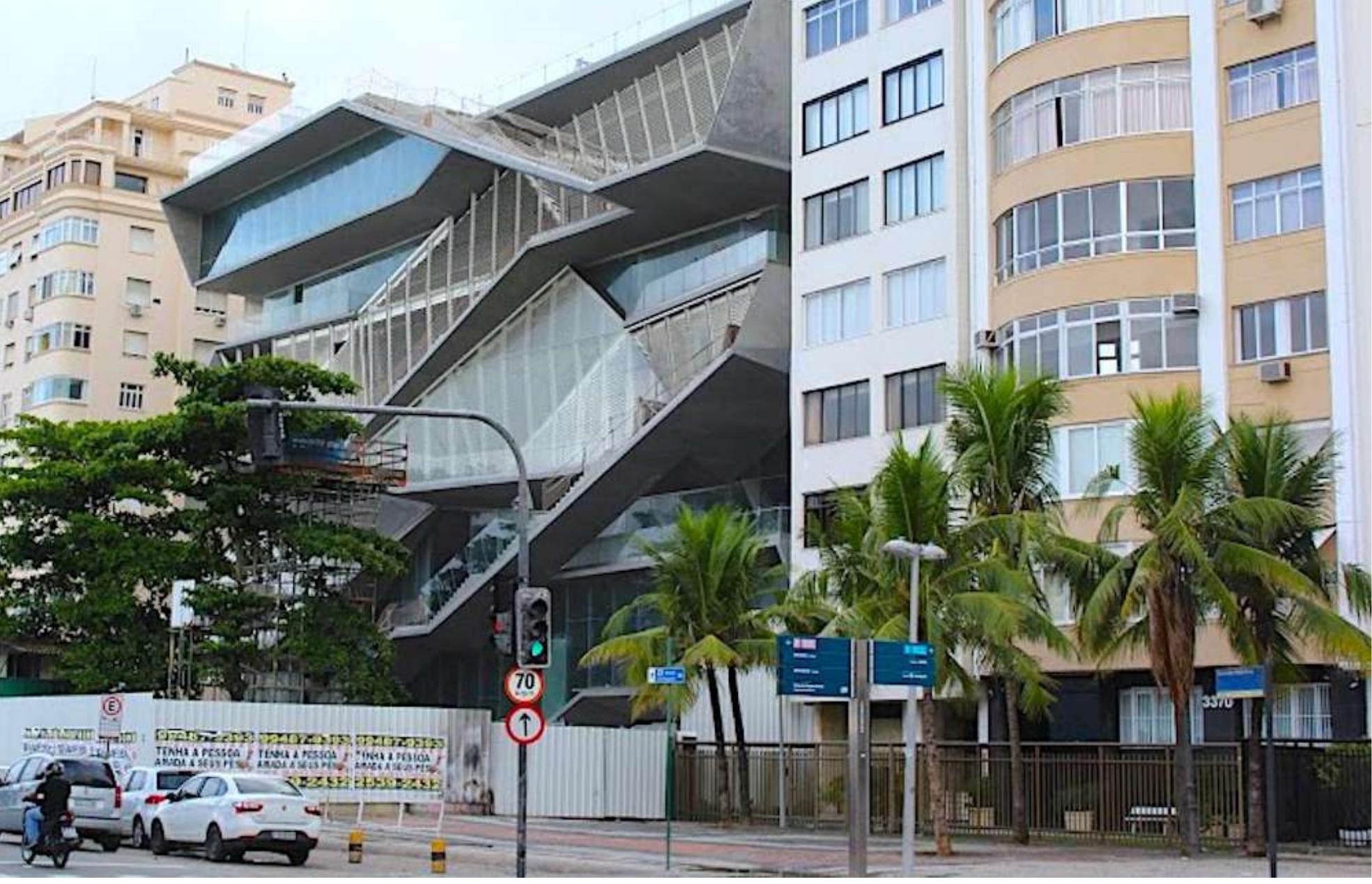

Figura 8. Vista general del MIS, todavia en construcción. Fuente: Foto del autor, 2017.

Así como en el proyecto ganador, la volumetría del museo imaginado por el arquitecto japonés contrasta con la morfología circundante. Conocido por el experimentalismo con materiales y técnicas innovadoras, Ban diseñó un museo suspendido en una clase de burbuja definida por sus característicos entramados de madera y membrana, liberando el piso bajo como zona multifuncional abierta a la ciudad. El argumento formal revela la superficialidad, estereotipada y extemporánea, del conocimiento del arquitecto acerca de Brasil: la referencia al cuerpo femenino, a partir de la recuperación de los discursos de Oscar Niemeyer (Viana, 2014, p. 167). El resultado, además de caricato, es un objeto de carácter autónomo que ni siquiera busca relacionarse al terreno, al paisaje o a la morfología del entorno.

Ya Libeskind parte de la identificación de ejes abstractos trazados a partir de la localización de los hitos geográficos de la ciudad, como el Pan de Azúcar, el Cerro Dos Hermanos y el Corcovado, para estructurar la forma del museo como el más nuevo icono a participar del paisaje. A esto sobrepuso, de forma poco clara, partituras musicales y un texto del poeta Haroldo Campos, perteneciente al movimiento concretista brasileño. Su capacidad de combinar partes de manera a conformar una sintaxis narrativa potente, como la elaborada en el Museo Judio de Berlín (1988), no se repite en el MIS, donde la inserción de planos y vidrieras de colores torna el resultado global débil y caricatural, asemejándose al "sombrero de frutas de Carmen Miranda" (ibídem, 95) (Figura 8). 
De hecho, la alusión a Carmen Miranda parece ser bastante adecuada para ilustrar la visión contaminada por el exotismo que se construyó sobre Brasil a lo largo del siglo XX. Su figura exuberante representa con maestría la imagen tipo exportación, muy conveniente a los tiempos de masificación cultural, que subyace en canciones como South American Way (1939).

\section{Conclusión: la mirada extranjera y nosotros}

La presencia de arquitectos de fama internacional en Brasil pone en tela de juicio una serie de cuestiones acerca de la mirada extranjera sobre nosotros, los latinoamericanos, pero también alerta sobre la manera en que nosotros mismos nos hemos mirado.

Los proyectos, brevemente aquí analizados, son meros atisbos de un esquema interpretativo mucho más amplio y complejo que desborda los límites de la arquitectura y se adentra el campo de la historia de las ideas y de la geopolítica internacional. La circulación de arquitectos alrededor del mundo expone las ambigüedades de los tiempos globalizados: mientras se busca un carácter hipermoderno internacional, los viejos estereotipos son reforzados.

Referenciar la cultura y la arquitectura moderna del país parece ser casi una obligación de los extranjeros que han proyectado en Brasil recientemente. Ahora bien, las obras estudiadas demuestran que hay matices en la forma de trabajar con tal universo referencial. La Fundación Iberê Camargo revela que involucrarse personalmente y conocer profundamente el pais resultan en una narrativa arquitectónica bien constituida y compleja; algo extensible a la Ciudad

de las Artes de Portzamparc, aunque su estructuración referencial parta de un despliegue de imágenes más fácilmente identificables.

Ya en los museos diseñados por Calatrava y Diller Scofidio + Renfro los puntos fuertes y débiles que poseen no parecen tener relación con los diálogos que dicen intentar establecer con el lugar desde su punto de vista histórico y cultural, siendo, por lo tanto, dispensables. El propio Calatrava relativiza la dicotomía local/global:

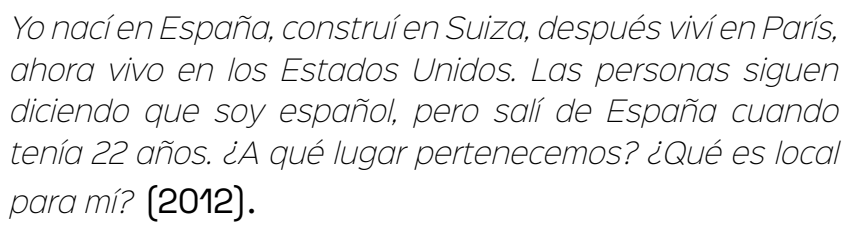

La pregunta de Calatrava puede ser extendida a un contexto en donde la globalización ha borrado las fronteras atribuidas a las nacionalidades individuales de los arquitectos, desdibujando las líneas mismas que distinguían lo "propio" de lo "ajeno". De ahí surge una interrogante a la que este breve texto no pretende responder, pero sobre la que juzga importante reflexionar: ¿puede la arquitectura de los starchitects ser latinoamericana?

Finalmente, los proyectos no ejecutados de Nouvel, Ban y Libeskind son los más típicos representantes de una visión estigmatizada y prejuiciosa sobre el país del "samba, fútbol y carnaval". En efecto, el imaginario de un mundo natural, salvaje y sin cultura, en contraste con otro supuestamente mejor y más civilizado acompaña a los países latinoamericanos desde los tiempos coloniales. Creado por el europeo y reforzado por la constitución de nuestra autoimagen 
inicial, este pensamiento está marcado por un reconocimiento del retraso y subdesarrollo cultural y económico frente a Europa

La imagen de una América Latina única, pobre pero alegre, ignorante pero vital, conviene justamente a la mirada de las culturas hegemónicas (Perrone-Moisés, 1997, p. 252).

Anacrónica y disconforme con el propio contexto globalizado, esa clase de lectura revela la persistencia de una mirada que aún divide el mundo entre "centro y periferia", ignorando las tendencias de descentramiento observadas por Marina Waisman que ponen en crisis los modelos hegemónicos y favorecen el pluralismo existente en los diversos proyectos locales (2013, p. 86).

Cabe resaltar que, a diferencia del "centro", la "periferia" siempre estuvo abierta a los aportes culturales exógenos. La identidad cultural brasileña, y latinoamericana, se ha formado y transformado con base en diferentes tradiciones, cruces y mezclas culturales, cada vez más familiares al mundo globalizado, demostrando que la convivencia entre identidad y diferencia no necesariamente deviene anulación recíproca.

Por último, es importante ampliar el alcance del análisis del objeto arquitectónico para llegar a las motivaciones que están por detrás de muchos de estos grandes equipamientos culturales de visibilidad internacional. Partícipes de pretensiosos planes de transformación urbana relacionados con los grandes eventos deportivos y al deseo de, una vez más, enseñar a los "paises centrales" un alto grado de avance civilizatorio, estas obras están inspiradas en modelos "exitosos" experimentados en Europa y Estados Unidos, cuyo paradigma se remonta a la inauguración del parisino Centro Pompidou en 1977, de Richard Rogers y Renzo Piano, que posteriormente seria renovado por el Guggenheim proyectado por Gehry en Bilbao.

Si hay algo que une a los diversos países latinoamericanos es la condición urbana. La arquitectura que contribuye a la ciudad debe buscar soluciones y respuestas que comprendan y aprecien las características de las complejas ciudades del subcontinente, alejándose de una visión que entiende la ciudad europea como ideal o mejor. Por consiguiente, si hay algo de equivocado en la forma cómo los extranjeros construyen su mirada hacia nosotros, igualmente debemos reflexionar acerca de la manera cómo nosotros mismos nos hemos interpretado. 


\section{Referencias bibliográficas}

Arantes, P. F. (2012). Arquitetura na era digital-financeira: desenho, canteiro e renda da forma (1 ed.). São Paulo: Editora 34.

Calatrava, S. (2012). Entrevista a Pedro Rivera. AU - Arquitetura e Urbanismo, 220, 2012. Recuperado de: http://www.au.pini. com.br/arquitetura-urbanismo/220/artigo262129-2.aspx

Candido, A. (1985). Literatura e sociedade. São Paulo: Companhia Editora Nacional.

Comas, C. E. D. (2008). Fundação Iberê Camargo: a transparência do concreto. Arqtexto/Propar UFRGS, 13, 122-145.

Diller Scofidio + RENFRO (2010). Museum of Image and Sound. Recuperado de: https://dsrny.com/project/rio-mis?index $=f$ alse\&tags $=$ cultural\&section $=$ projects

Figueira, J. (2012). Memória descritiva duma relação amorosa entre Arquiteturas separadas pelo Atlântico e outras correntes misteriosas. Revista Camões, 21, 5-6.

Frampton, K. (2008). Museum as labyrinth. En KIEFER, F. (ed.) Iberê Camargo Foundation. São Paulo: Cosac \& Naify, pp. 90-105.

Kiefer, F. (2010). Linhas que se cruzam. CDO - Cadernos d'Obra. Revista Científica Internacional de Construção da Faculdade de Engenharia da Universidade do Porto, 2, 130-131.

Leonídio, O. (2008). Cidade da Música do Rio de Janeiro: a invasora. Arqtexto/Propar UFRGS, 12, 176-191.

Leonídio, 0. (2009). Álvaro Siza Vieira: another void. Log Magazine, 16, 27-38.

Machabert, D. y Beaudoin, L. (2009). Álvaro Siza - Uma questão de medida. Uma maneira de fazer portuguesa - a propósito de Fernando Távora. Sintra: Caleidoscópio.

Milheiro, A. V. (2007). A Minha Casa ÉUm Avião. Lisboa: Relógio D’Água Editores.

Moneo, R. (2008). Inquietação teórica e estratégia projetual na obra de oito arquitetos contemporâneos. São Paulo: Cosac Naify.

Montaner, J. M. (2003). Museos para el nuevo siglo. Barcelona: Gustavo Gili.

Mahfuz, E. (2000). Siza em POA. Arqtexto/Propar UFRGS, 0, 124-125.

Moix, L. (2016). Queríamos un Calatrava. Viajes arquitectónicos por la seducción y el repudio. Barcelona, Anagrama.

Nouvel, J. y Jodidio, P. (ed.) (2008). Jean Nouvel by Jean Nouvel. 1993-2008. Colonia: Taschen.

Perrone-Moisés, L. (1997). Paradoxos do nacionalismo literário na América Latina. Estudos Avançados, 11 (30), 245-259.

Pessoa, D. (2015). Arquiteto espanhol Santiago Calatrava fala sobre o Museu do Amanhã e o Rio. Revista Veja Rio, 13 jun. 2015. Recuperado de: https://vejario.abril.com.br/cidades/arquitetoespanhol-santiago-calatrava-fala-sobre-detalhes-construcaomuseu-do-amanha-e-sobre-o-rio/\#

Portzamparc, C. (2008). Filiações franco-brasileiras... Do Rio de Agache à Cidade da Música. Arqtexto/Propar UFRGS, 13, 152-175.

Portzamparc, C. (2009). Apresentação. En SEGRE, R. (org.). Tributo a Niemeyer. Río de Janeiro: Viana \& Mosley, pp. 9-11.

Portzamparc, C. (2013). Cidade das Artes. Recuperado de: http://www.christiandeportzamparc.com/en/projects/cidade-das-artes

Siza, A. S. (1995). Obras e projetos. Matosinhos: Centro Galego de Arte Contemporânea, 1995.

Siza, A. (2012). Paredes retas e superfícies onduladas. AU-Arquitetura e Urbanismo, 220, 40-51.

Viana, L. Q. (2014). Arquitetura entre conexões contemporâneas. O concurso para o novo Museu da Imagem e do Som do Rio de Janeiro. Tesis de doctorado, Universidade Federal do Rio de Janeiro, PROARQ, RJ, Brasil.

Waisman, M. (2013). O interior da História: historiografia arquitetônica para uso de latino-americanos. São Paulo: Perspectiva.

Wisnik G. (2008). Hipóteses acerca da Relação entre a Obra de Álvaro Siza e o Brasil. En J. Figueira (org.), Álvaro Siza. Modern Redux. Ostfirldern: Hatje Cantz Verlag, pp. 50-57.

Zabalbescoa, A. (2014). La lección de Brasil. El País-Cultura, 31 enero 2014. Recuperado de: https://elpais.com/cultura/2014/01/31/ actualidad/1391202377_268102.html 